\title{
ALFABETIZAÇÃO CIENTÍFICA E CRIANC̣A: ANÁLISE DE POTENCIALIDADES DE UMA BRINQUEDOTECA
}

\author{
AMANDA CRISTINA TEAGNO LOPES MARQUES ${ }^{*}$ \\ http://orcid.org/0000-0001-5418-2004 \\ MARTHA MARANDINO ${ }^{1 * *}$ \\ https://orcid.org/0000-0001-9175-012X
}

RESUMO: Este artigo analisa o potencial de uma brinquedoteca para a promoção da alfabetização científica (AC) de crianças. Para a produção de dados, realizou-se observação e registro de três áreas de uma brinquedoteca. A análise foi realizada com base na ferramenta teóricometodológica de indicadores e atributos de alfabetização científica. Como principais referenciais teóricos destacamse discussões sobre alfabetização científica como processo que ocorre dentro e fora da escola e implica a apropriação de elementos da cultura científica com vistas à participação social. A discussão sobre infância foi realizada com base nos aportes da Sociologia da Infância, e brincar/brinquedo foram conceituados especialmente a partir de Brougère. Conclui-se que a brinquedoteca, ao inserir em seu espaço, áreas e objetos que remetem a temas científicos, pode contribuir para o processo de AC de crianças, possibilitando a aproximação entre culturas infantis e elementos da cultura científica.

Palavras-Chave: Alfabetização científica; Criança; Brinquedoteca.

\section{SCIENTIFIC LITERACY ANDCHILD: ANALYSIS OF POTENTIALITIES OF A TOY LIBRARY}

ABSTRACT: This article analyzes the potential of a toy library for promoting children's scientific literacy (SL). Data was produced through observation and registration of three areas of a toy library. The analysis was based on the theoretical-methodological tool formed by indicators and attributes of scientific literacy. As the main theoretical references, the article highlights discussion about scientific literacy as a process that takes place inside

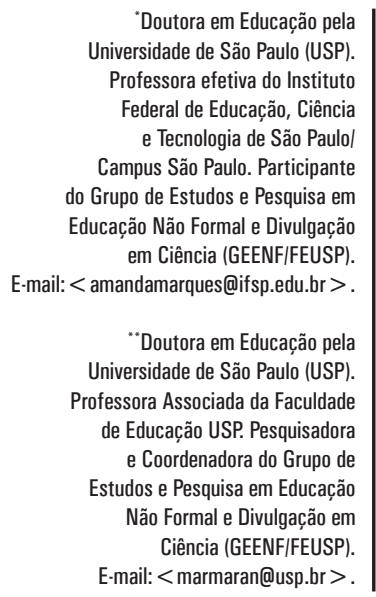

I Instituto Federal de Educação, Ciência e Tecnologia de São Paulo, Campus São Paulo, SP - Brasil.

" Universidade de São Paulo, Faculdade de Educação, São Paulo, SP - Brasil. 
and outside school and implicates appropriation of scientific culture elements to enable social participation. The discussion about childhood was made based on Sociology of Childhood approach, and play/ toy were conceptualized especially from Brougère. The article concludes that the toy library, with objects that refer to scientific themes, contributes to children's SL process, allowing an approximation between childhood cultures and elements of scientific culture.

Keywords: Scientific literacy; Child; Toy library.

\section{ALFABETIZACIÓN CIENTÍFICA YEL NIÑO: ANÁLISISDE POTENCIALIDADES DE UNA LUDOTECA}

RESUMEN: Este artículo analiza el potencial de una ludoteca para la promoción de la alfabetización científica (AC) de niños. Para la elaboración de datos, se realizaron observación y registro de tres áreas de una ludoteca. El análisis se realizó basándose en la herramienta teórico-metodológica de indicadores y atributos de la alfabetización científica. Se destacan como las principales referencias teóricas las discusiones sobre alfabetización como proceso que ocurre dentro y fuera de la escuela e implica la apropiación de elementos de la cultura científica con el objetivo de la participación social. La discusión sobre la infancia se realizó con base en las contribuciones de la Sociología de la Infancia, y jugar/juguete se conceptuaron especialmente a partir de Brougère. Se concluye que la ludoteca, cuando incluye en su espacio áreas y objetos que se refieren a temas científicos, puede contribuir al proceso de AC de los niños y posibilitar el acercamiento de las culturas infantiles a elementos de la cultura científica.

Palabras Clave: Alfabetización científica; Niño; Ludoteca. 


\section{INTRODUÇÃO}

No campo da educação em ciências, discussões sobre alfabetização científica (AC) têm ocupado lugar de destaque no cenário atual. $\mathrm{Na}$ literatura, propõe-se muitas vezes a articulação entre educação científica e formação para a cidadania, considerando a importância da apropriação do conhecimento científico para a participação na sociedade e nos processos de tomada de decisão (BYBEE, 1995; LAUGKSCH, 2000; SANTOS, 2007; CACHAPUZ et al., 2011; MILLER, 1998; GARFIELD, 1988).

O processo de alfabetização científica não ocorre exclusivamente na escola, fazendo-se necessário destacar o potencial de espaços de educação não formal na promoção da AC da população (KRASILCHIK, MARANDINO, 2007; HENRIKSEN, FROYLAND, 2000; PÉREZ, MOLINÍ, 2004). Segundo Trilla et al. (2003, p. 11), a educação não formal (ENF) "se refere a todas aquelas instituições, atividades, meios, âmbitos da educação que, não sendo escolares, foram criados expressamente para satisfazer determinados objetivos educativos".

No que toca às potencialidades de espaços de ENF para a educação científica de crianças em idade pré-escolar, pesquisas destacam a importância de projetar espaços com foco na criança (ISZLAJI, 2012; NEVES, MASSARANI, 2016; CARVALHO, LOPES, 2016; STUDART, 2005), considerando a necessidade de valorizar a brincadeira, as formas de expressão infantis, as múltiplas linguagens, a interação, a participação, a possibilidade de escolha, o desafio, a fantasia, a curiosidade. Nesse sentido, a pesquisa justifica-se em função da relevância e da necessidade de considerarmos a criança como sujeito do processo de alfabetização científica, atentando às especificidades da infância (MARQUES, MARANDINO, 2008).

O presente artigo insere-se nas discussões sobre alfabetização científica em espaços de educação não formal, tendo como foco a criança. Mais especificamente, interrogamo-nos acerca das potencialidades de uma brinquedoteca na promoção da alfabetização científica de crianças. Pergunta-se: "Uma brinquedoteca pode potencializar a AC de crianças? Que indicadores e atributos de AC estão presentes em três áreas de uma brinquedoteca?". Como objetivo de pesquisa, pretendemos identificar objetos, cenários e propostas de brincadeira presentes em uma brinquedoteca que se mostrem potencialmente favoráveis à promoção da alfabetização científica de crianças. Empregamos o termo "potencializar" e seus derivados no sentido de destacar que a análise indica possibilidades de promoção de AC via organização de espaços e objetos, ou seja, pretendemos identificar se a brinquedoteca pode fomentar, fortalecer ou estimular em alguma medida o processo de AC de crianças. Nesse contexto, falamos em potência, possibilidade, que pode ser concretizada ou não.

$\mathrm{O}$ artigo está organizado em quatro seções: na primeira, discutimos o referencial teórico da pesquisa, apresentando concepções de alfabetização científica, infância e brincar; a segunda seção é dedicada às questões metodológicas, apresentando a ferramenta de indicadores e atributos de AC; na terceira seção analisamos os dados coletados em três espaços de uma brinquedoteca e, na última, apresentamos considerações finais. 


\section{ALGUNS PONTOS DE ANCORAGEM: OS REFERENCIAIS TEÓRICOS}

\subsection{ALFABETIZAÇÃO CIENTíFICA E CRIANC̣A: UM DIÁLOGO POSSÍVEL?}

Com o objetivo de situar nosso objeto, discorremos nesta seção sobre as possibilidades de consideração da criança como sujeito do processo de alfabetização científica (AC), identificando os cuidados a serem tomados ao propormos esse movimento.

Diversos autores têm reconhecido a necessidade da alfabetização científica como parte da educação geral voltada a todos os cidadãos com vistas a possibilitar a participação no contexto social. Essa participação, em alguns casos, é assumida em uma perspectiva mais instrumental e com vistas a possibilitar o progresso científico (MILLER, 1998; GARFIELD, 1988; LAUGKSCH, 2000); em outros, defende-se uma perspectiva mais ampla, o que implica o alargamento das possibilidades de participação nos debates sociais e nos processos de tomada de decisão (CACHAPUZ et al., 2011; FOUREZ, 2003; CHASSOT, 2014). Para Fourez (2003), a perspectiva de alfabetização científica expressa-se em termos de finalidades humanistas (capacidade de situar-se em um universo técnico-científico e utilizar as ciências para decodificar seu mundo), sociais (diminuição das desigualdades produzidas pela falta de compreensão das tecnociências, ampliando as possibilidades de engajamento nos debates atuais), e econômicas (participação no mundo industrializado e reforço no potencial tecnológico). Em última instância, trata-se do questionamento a um modelo de ensino pautado na transmissão de informações com caráter propedêutico, e a defesa de que cabe às instâncias educativas formar cidadãos, e não especialistas.

Além da reconfiguração do papel da educação em ciências - que favorece a emergência da alfabetização científica como objetivo formativo -, assiste-se também ao alargamento da compreensão sobre os espaços nos quais ocorre a educação: a escola não é seu único lócus, em que pese sua centralidade no processo de democratização do conhecimento. Nesse sentido, há que reconhecer as potencialidades de espaços não-escolares na promoção da alfabetização científica da população, considerando as especificidades da ação educativa quando desenvolvida nesses contextos (público, discurso expositivo, objetos, etc.) (HENRIKSEN, FROYLAND, 2000; PÉREZ, MOLINÍ, 2004; MARANDINO et al., 2008; CERATI, 2014).

À luz do exposto, e com base na literatura sobre o tema (MILLER, 1998; GARFIELD, 1988; LAUGKSCH, 2000; FOUREZ, 2003; CHASSOT, 2014) sintetizamos nossa compreensão de alfabetização científica: trata-se de processo que ocorre dentro e fora da escola e que implica a) a promoção de diálogos e aproximações com a cultura científica; b) a apropriação de saberes relacionados a termos e conceitos científicos, à natureza da ciência, às relações entre ciência, tecnologia e sociedade; c) a promoção de condições necessárias à realização de leituras críticas da realidade, à participação no debate público, à tomada de decisão responsável, à intervenção social em uma perspectiva emancipadora e de inclusão social (MARQUES, MARANDINO, 2018). Entendemos que a AC deve promover a ampliação da leitura de mundo com vistas à inserção crítica na sociedade (FREIRE, 1989).

Considerar a AC como processo, direito e objetivo formativo, e entendê-la como 
imersão na cultura científica, possibilita compreendermos a criança como sujeito. A criança, enquanto pessoa, partícipe da sociedade, também se insere em um contexto que pode potencializar de maneira mais ou menos efetiva o processo de AC, a depender de como espaços e tempos estão organizados, considerando que as vivências das infâncias são tão diversas e particulares quanto os contextos concretos nos quais se inserem as crianças (JENKS, 1994; QVORTRUP, 1994; SARMENTO, 2005). Nesse sentido, entender a AC como processo implica considerar seu desenvolvimento desde a infância, em espaços escolares e não-escolares.

$\mathrm{A}$ dimensão da $\mathrm{AC}$ como direito significa considerar que todos temos o direito ao conhecimento, considerando seu potencial na formação de sujeitos críticos, capazes de realizar leituras de mundo ampliadas e compreender a realidade à sua volta. Compreensão e atuação que devem estar a serviço de um projeto de sociedade pautado na inclusão social, na superação das desigualdades e de todas as formas de opressão. Nesse sentido, também é direito da criança ter acesso à educação e à alfabetização científica.

Considerar a AC como objetivo formativo, por sua vez, implica promover uma educação em ciências que de fato possibilite a formação de pessoas capazes de participar nos debates públicos e intervir na sociedade, compreendendo termos, conceitos, procedimentos do campo científico, a natureza da ciência e o(s) modo(s) de produção do conhecimento científico em sua interação com os contextos social, político, econômico e cultural e, ainda, capaz de perceber relações entre ciência, tecnologia, sociedade e ambiente. No caso específico da criança, buscase promover a aproximação a elementos da cultura científica, partindo de uma compreensão de ciência como produção social e historicamente situada. A proposta de "aproximação" à ciência implica construir contextos nos quais elementos da cultura científica estejam presentes, em diálogo com as culturas das infâncias.

Mas de que criança e de qual(is) infância(s) tratamos, afinal? Delinear o conceito de AC de modo a considerar as especificidades da criança demanda, necessariamente, olhar para esse sujeito, indicando a compreensão de infância que orienta nossas discussões. Faremos isso no próximo tópico.

\subsection{CRIANÇA, INFÂNCIA E INFÂNCIAS}

Sarmento (2003) inicia um de seus textos referindo-se à imagem de duas crianças que brincam de boneca em um campo de refugiados em Kosovo; a cena ilustra a tese por ele defendida no artigo: a de que o imaginário infantil constitui uma importante característica da forma de relação das crianças com o mundo.

Entre as crianças que brincam com uma Barbie, ou que chutam um crânio humano, ou que empunham uma Kalashnikov de plástico, ou que jogam ao berlinde, ou lançam o peão, ou brincam à casinha, ou se divertem na consola ou no écran do computador há todo um mundo de diferenças: de condição social, de contexto, de valores, de referências simbólicas, de expectativas e possibilidades. Mas há também um elemento comum: a experiência das situações mais extremas através do jogo e da construção imaginária de contextos de vida. (SARMENTO, 2003, p. 2). 
A produção de Sarmento situa-se no movimento teórico que busca superar definições psicologizantes (que compreendem a infância exclusivamente do ponto de vista biológico) e sociologizantes (que consideram a criança como objeto passivo do processo de socialização) da infância; tratase de construir uma concepção de criança como pessoa, partícipe de um contexto social (como indicado no excerto acima), mas também produtora de cultura (CORSARO, 2011; JENKS, 1994; SARMENTO, 2003). Busca-se romper com o modelo de déficit ao qual se alinham compreensões modernas da infância (a criança caracterizada como aquele que não fala, não trabalha, não tem direitos políticos, não tem pensamento racional), sublinhando que é da ordem da diferença, e não do déficit, o que distingue a criança (em seu imaginário) do adulto (SARMENTO, 2003).

A dimensão social da construção da infância - ou das infâncias implica considerar que, ainda que existam características comuns às crianças e à infância, as experiências concretas distinguem-se no tempo e no espaço, ou seja, as vivências da infância são múltiplas e singulares; por esse motivo falamos em "infâncias" no plural:

O imaginário infantil é inerente ao processo de formação e desenvolvimento da personalidade e racionalidade de cada criança concreta, mas isso acontece no contexto social e cultural que fornece as condições e as possibilidades desse processo. As condições sociais e culturais são heterogêneas, mas incidem perante uma condição infantil comum: a de uma geração desprovida de condições autônomas de sobrevivência e de crescimento e que está sob o controle da geração adulta. A condição comum da infância tem a sua dimensão simbólica nas culturas da infância. (SARMENTO, 2003, p. 3).

Por culturas da infância entende-se "a capacidade das crianças em construírem de forma sistematizada modos de significação do mundo e de ação intencional, que são distintos dos modos adultos de significação da ação" (SARMENTO, 2003, p. 3-4). As crianças produzem cultura em um processo denominado por Corsaro (2011) de "reprodução interpretativa": à medida em que se inserem no mundo, não apenas se apropriam dos códigos culturais nele presentes, mas os recriam e interpretam criativamente. A inserção da criança no contexto social não se dá, portanto, de forma passiva; a discussão sobre as culturas infantis implica considerar a produção cultural para as crianças, as formas de recepção desses produtos pelas crianças, e as formas autônomas por elas produzidas, como os jogos infantis, os modos de significação e uso da linguagem, em um processo simultaneamente criativo e reprodutivo (SARMENTO, 2003). As culturas infantis são, essencialmente, culturas de pares (CORSARO, 2011), contextualizadas temporal e socialmente, construídas nas relações inter e intrageracionais, o que implica compreender a infância como categorial geracional (JENKS, 1994).

Autores como Benjamin (2009) e Fernandes (2004) já consideravam a criança como ser social e produtor de cultura. Para Benjamin (2009, p. 94), "as crianças não constituem nenhuma comunidade isolada, mas antes fazem parte do povo e da classe a que pertencem." O autor destaca a importância 
do imaginário infantil na brincadeira, e a capacidade de criação da criança. O sociólogo brasileiro Florestan Fernandes também considera as crianças sujeitos sociais dotados de cultura própria. Debruçando-se sobre o folclore infantil, estudou os grupos infantis e identificou uma cultura que abrange não apenas o folclore (brincadeiras, jogos e cantigas), mas outros elementos que compõem as relações estabelecidas entre os pares (FERNANDES, 2004).

À luz das concepções apresentadas, partimos do entendimento de que a criança pode ser considerada sujeito da AC, sem que isso represente a supressão daquilo que caracteriza a criança e suas infâncias: as múltiplas linguagens, o brincar, as interações, a fantasia, as formas próprias de ser e de estar no mundo (CORSARO, 2011; SARMENTO, 2003). Isso significa tomar a criança como ponto de partida, e possibilitar sua aproximação a elementos da cultura científica (conceitos, termos, procedimentos, linguagem etc.) a partir de vivências que respeitem seus tempos e dialoguem com suas infâncias. Trata-se, a nosso ver, de incluir as crianças em ações educativas que potencializem a alfabetização científica, sem que isso signifique desconsiderar as peculiaridades das infâncias. Como fazê-lo?

\subsection{A BRINQUEDOTECA, O BRINQUEDO E A APROPRIAC̣ÃO DE CÓDIGOS CULTURAIS}

A brinquedoteca configura-se como o espaço criado com o objetivo de proporcionar estímulos para que a criança possa brincar livremente (CUNHA, 1997), e representa a valorização da atividade lúdica da criança. É espaço de criatividade, imaginação, sensibilidade, descoberta de novos significados em respostas a experiências construídas de maneira autônoma pela criança. Constitui um espaço de "aprendizagens incidentais" (KISHIMOTO, 2011), no qual deve ser assegurado à criança o direito de brincar livremente, e de utilizar os brinquedos de acordo com suas motivações (KISHIMOTO, 2011).

O brinquedo é o objeto, suporte da brincadeira (KISHIMOTO, 2011), e possibilita o acesso a determinados elementos da cultura, ou a representações de elementos da cultura (BROUGÈRE, 2008), o que pode incluir a cultura científica. O brinquedo coloca a criança em contato com significações culturais que se apresentam na dimensão material do objeto. Ainda que não condicione a apropriação de determinadas imagens culturais, havendo a possibilidade de transgressão, ele "influencia e estrutura a cultura lúdica da criança tanto no nível das condutas lúdicas quanto no dos conteúdos simbólicos” (BROUGÈRE, 2008, p. 57). Quer dizer, a brincadeira da criança está parcialmente ligada aos objetos lúdicos de que ela dispõe, do que decorre a importância de analisar que objetos são esses e quais representações eles podem veicular.

Brougère (2008) caracteriza o brinquedo como objeto que suporta uma representação, produto de uma sociedade com traços culturais específicos. O brinquedo não é definido por uma função precisa, pois nele prevalece o valor simbólico: "trata-se, antes de tudo, de um objeto que a criança manipula livremente, sem estar condicionada às regras ou a 
princípios de utilização de outra natureza." (BROUGÈRE, 2008, p. 13).

Da mesma forma, a brincadeira - ação do sujeito sobre o brinquedo - escapa a qualquer função precisa; pode fabricar seus objetos, desviandoos de seu uso habitual (uma vara de pesca pode se transformar em espada, por exemplo), e caracteriza-se por ser uma atividade livre. Isso não significa desconsiderar o papel do brinquedo como suporte: "O objeto tem o papel de despertar imagens que permitirão dar sentido a essas ações. O brinquedo é, assim, um fornecedor de representações manipuláveis, de imagens com volume (...)." (BROUGËRE, 2008, p. 14). Nesse sentido, o brinquedo apresenta possibilidades de ações coerentes com a representação, ainda que a criança, ao brincar, possa transgredir a simbolização sugerida, pois a brincadeira pode escapar ao brinquedo.

Auxilia-nos a conceituação apresentada por Brougère (2008), que define os brinquedos de duas maneiras: primeiramente em relação à brincadeira, e em segundo lugar em relação a uma representação social. No primeiro caso, "o brinquedo é aquilo que é utilizado como suporte numa brincadeira" (BROUGERE, 2008, p. 62), podendo ser um objeto manufaturado, uma sucata, ou um objeto adaptado. "Tudo, nesse sentido, pode se tornar um brinquedo e o sentido de objeto lúdico só lhe é dado por aquele que brinca enquanto durar a brincadeira" (BROUGËRE, 2008, p. 62-3). No segundo caso, o brinquedo é um objeto reconhecido como tal em função de suas características, sendo a materialização de um projeto do adulto destinado à brincadeira da criança; nesse caso, o objeto, sendo utilizado ou não em situação de brincadeira, conserva seu caráter de brinquedo.

Brougère (2008, p. 16) afirma que "conceber e produzir um brinquedo é transformar em objeto uma representação, um mundo imaginário ou relativamente real." Quer dizer, o brinquedo comporta uma representação da realidade, mas não reproduz o mundo real, e sim "produz, por modificações, transformações imaginárias” (BROUGËRE, 2008, p. 43), colocando a criança em contato com significações culturais que se apresentam na dimensão material do objeto.

Mas o processo de construção de referências culturais pela criança por meio do brinquedo não se faz de maneira passiva; ao contrário, a criança, pela brincadeira, envolve-se em um papel ativo de manipulação e transformação das imagens que lhe são fornecidas pelo brinquedo, inserindo-se em um processo dinâmico de inserção cultural. E é no papel ativo da criança que reside a especificidade do brinquedo em relação a outros suportes culturais: "a criança, na maior parte das vezes, não se contenta em contemplar ou registrar as imagens: ela as manipula na brincadeira e, ao fazê-lo, transformaas e lhes dá novas significações.” (BROUGÈRE, 2008, p. 47)

Ainda que o brinquedo não condicione a apropriação de determinadas imagens culturais, havendo a possibilidade de transgressão, ele "influencia e estrutura a cultura lúdica da criança tanto no nível das condutas lúdicas quanto no dos conteúdos simbólicos" (BROUGĖRE, 2008, p. 57). Quer dizer, a brincadeira da criança está parcialmente ligada aos objetos lúdicos de que ela dispõe. 
A brincadeira possibilita a entrada na cultura lúdica ${ }^{1}$ (BROUGÈRE, 2008), mas também na cultura de uma forma mais ampla. E, nesse contexto, o brinquedo se apresenta como estruturante do conteúdo da brincadeira, apresentando à criança imagens, representações e universos imaginários. Daí a importância de analisar os objetos colocados à disposição da criança; os brinquedos apresentam conteúdo às brincadeiras, potencializando o acesso a certas imagens culturais. E foi sobre eles que a presente pesquisa se debruçou, com vistas a identificar o potencial de uma brinquedoteca na $\mathrm{AC}$ de crianças.

\section{SOBRE O PERCURSO METODOLÓGICO}

Para produção de dados, foi realizada pesquisa qualitativa junto à brinquedoteca do LABRIMP - Laboratório de Brinquedos e Materiais Pedagógicos -, da Faculdade de Educação da Universidade de São Paulo, Brasil. A luz da classificação de Marandino et al. (2009), em relação ao foco de pesquisa temos um estudo de concepção, ${ }^{2}$ já que nos interessa o espaço da brinquedoteca, sua organização e potencialidades, e não o modo como se dá a aprendizagem do público. Como unidade de estudo, apontamos a exposição, ${ }^{3}$ ou seja, o modo como o espaço da brinquedoteca está organizado, com atenção especial a objetos e cenários potencialmente interessantes à $\mathrm{AC}$ de crianças. Como procedimentos de coleta de dados realizamos observação (com registro em notas de campo, e registro fotográfico de espaços e materiais). Para análise dos dados produzidos na observação, adaptamos uma ferramenta teórico-metodológica de indicadores de AC inicialmente proposta por Cerati (2014), considerando que indicadores e atributos propostos pela autora permitem identificar elementos potencializadores da AC tanto nas exposições quanto no público. Para este trabalho, a ferramenta foi revista de modo a contemplar a criança e será detalhada a seguir.

\subsection{A FERRAMENTA TEÓRICO-METODOLÓGICA DE INDICADORES DE ALFABETIZAÇÃO CIENTÍFICA PARA CRIANC̣AS}

Indicadores são informações qualitativas ou quantitativas que expressam o desempenho de um processo (FNQ, 2016). À luz de Cerati (2014) e Oliveira (2016), utilizamos nesta pesquisa uma ferramenta teórico-metodológica de indicadores e atributos ${ }^{4}$ de AC, adaptada especificamente para o público infantil (MARQUES et al., 2017). A ferramenta pode ser empregada tanto para análise de ações de divulgação científica (objetos, exposições, mediação etc.) quanto do público e sua percepção sobre a ação, ou seja, ela foi construída de modo a poder ser adaptada aos dois enfoques. Nesse sentido, ajuda-nos a avaliar ações de divulgação científica a partir tanto da concepção quanto da recepção (MARANDINO et al., 2009), de forma separada ou articulada; não se trata apenas de identificar a presença ou a ausência dos atributos, mas de avaliar a ação a fim de aprimorá-la de modo que responda às intenções educativas. 
Passemos, então, à apresentação de indicadores e atributos.

1. Indicador de conbecimento científico. Este indicador inclui a aproximação e/ou a apropriação de ideias, termos, conceitos e procedimentos científicos, bem como a reflexão sobre a natureza da ciência e seu processo de produção (AKERSON et al., 2011; BYBEE, 1995; NGSS, 2013; NORRIS, PHILIPS, 2003), considerando que a compreensão de conteúdos científicos é o ponto de partida para o processo de AC dos indivíduos (NORRIS, PHILIPS, 2003; ROBERTS, 2007). Incluem-se questões que dizem respeito à dinâmica interna da ciência, seu processo de produção e seu caráter histórico e humano (AULER, DELIZOICOV, 2001). O indicador propõe analisar em que medida os elementos supracitados se fazem presentes na brinquedoteca, promovendo aproximações entre a cultura da criança e elementos da cultura científica (FAGGIONATORUFINO, 2012). É composto pelos seguintes atributos: 1 a Conhecimentos e conceitos científicos. Aproximação a ideias, termos, conceitos (com explicitação ou não de seus significados) do campo científico. No caso da criança, falamos de "aproximação" a ideias, termos e conceitos do campo científico, o que não implica, necessariamente, sua apropriação, considerando o caráter processual da $\mathrm{AC}$ e da aprendizagem de conceitos científicos (VYGOTSKY, 2003). Trata-se de verificar a presença de elementos que aproximem a criança ao universo da ciência. 16 Pesquisas científicas. Aproximação aos resultados obtidos sobre o tema central das investigações no campo das ciências naturais, bem como resultados atuais globais do avanço do conhecimento e pesquisas que estão sendo desenvolvidas na atualidade. 1c Processo de produção de conbecimento científico. Possibilidade de contato com processos, procedimentos e instrumentos do campo científico, bem como a vivência de métodos e procedimentos da ciência (como formulação de hipóteses, realização de testes, registros, observações). 1d Papel do pesquisador no processo de produção do conbecimento. Referência a pesquisadores envolvidos no processo de produção da ciência, e possibilidade de reconhecimento da ciência como produção humana e histórica. 1e Dinâmica interna da ciência. Refere-se às concepções de ciência que fundamentam as compreensões sobre seu processo de produção, abarcando tanto seu caráter evolutivo e questionável, como histórico e filosófico. Inclui a possibilidade de reconhecimento de que as explicações científicas têm um caráter questionável e um grau de incerteza, considerando conflitos e controvérsias internas a sua produção.

2. Indicador Interface Social. Neste indicador avalia-se o potencial da ação de divulgação científica na promoção do entendimento do significado social da ciência e das relações entre ciência, tecnologia, sociedade e ambiente (CTSA), bem como a influência da participação da sociedade diante da Ciência, Tecnologia e Inovação (C,T\&I). O indicador abrange reflexões sobre o impacto da ciência na sociedade, riscos e benefícios da produção científica, questões éticas e controvérsias envolvidas no processo de 
produção científica (AULER, DELIZOICOV, 2001; FOUREZ, 2003), dando margem à aplicação do conhecimento no cotidiano e à compreensão de suas consequências, auxiliando na participação nos debates da atualidade e na tomada de decisão (CERATI, 2014). Contempla o princípio da participação social, entendido como a possibilidade de tomada de decisão fundamentada no contexto das práticas sociais (LEWENSTEIN, BROSSARD, 2006; SANTOS, MORTIMER, 2001; SIS CATALYST, 2013). Atributos: 2 a Impactos da ciência na sociedade. Estabelecimento de conexões do conhecimento científico com o cotidiano e com as vivências pessoais das crianças, resolução de problemas sociais, contato com impacto da ciência na sociedade, os riscos e benefícios do desenvolvimento da CT\&I. 2 b Influência e participação da sociedade diante da ciência. Este atributo é identificado quando a ação potencializa a participação dos indivíduos, de forma individual e coletiva, nas decisões sobre ciência e a utilização dos resultados da ciência para engajamento, tomada de decisões e empoderamento. Inclui ainda, um aspecto relacionado à legitimidade de outras formas de conhecimento e à valorização dos saberes locais na pesquisa, ampliando as perspectivas de diálogo, de participação e de tomada de decisão.

3. Indicador Institucional. Analisa-se a política institucional em relação à missão, ações e público-alvo (ACHIAM, MARANDINO, 2014; KRASILCHIK, 2009), considerando se a instituição acolhe a criança e promove ações de divulgação científica (DC) que incluam o público infantil. Analisa-se também se a ação potencializa a aproximação à ciência em sua dimensão institucional, ou seja, a dimensão das instituições envolvidas na produção e fomento da ciência. Atributos: 3 a Política e missão institucional. Avaliase a promoção de ações de DC como produção de materiais, oficinas, visitas monitoradas especialmente voltadas à criança identificada na missão da instituição. 36 Identificação das instituições envolvidas na produção, fomento e divulgação da ciência. Identificação de instituições executoras e/ou colaboradoras dos projetos, como órgãos governamentais e/ou privados envolvidos no fomento e na divulgação da ciência.

4. Indicador de Interação. Neste indicador avalia-se tanto a capacidade da ação de divulgação científica na sensibilização, na promoção de envolvimento e na participação do público infantil (JENSEN, 1994; PISCITELLI, EVERETT E WEIER, 2003), quanto a maneira com que as crianças interagem e a qualidade das interações do ponto de vista físico, estético-afetivo e cognitivo. Atrelada à perspectiva cognitiva de que o conhecimento é construído por meio da interação com objetos e pessoas potencializando o processo de AC da criança (ANDERSON et al., 2002), o atributo ressalta a expressão de sentimentos por meio de linguagens (EDWARDS, GANDINI E FORMAN, 1999), o estímulo para uma relação interativa e dialógica entre os diversos atores envolvidos e os processos de aprendizagem, tanto na forma de interagir e usar o espaço/objeto à luz dos conhecimentos e experiências prévias, quanto 
na promoção de habilidades investigativas (ASH, 1999) na relação dos sujeitos com os objetos de conhecimento científico. Cabe ressaltar que a divisão em atributos de interação física, estético-afetiva e cognitiva justifica-se apenas para fins de análise, uma vez que na ação esses elementos aparecem integrados. Atributos: 4 a Interação física. Oportunidade de toque, manipulação e/ou outro procedimento de interação (como apertar botões, girar manivelas, movimentar, usar o teclado de um computador, trocar peças, etc.) para produção de um resultado. A questão do ritmo e do tempo (velocidade com que se executam as atividades) da criança em sua interação com o espaço/objeto é incluída neste atributo, considerando a dimensão temporal do ambiente (FORNEIRO, 2008). 4 b Interação estéticoafetiva. Possibilidade de respostas pessoais com emoções (como prazer, raiva, alegria, nojo, choque, medo, tristeza etc.) e respostas incorporadas (como movimentos e gestos) em relação aos conhecimentos científicos abordados e/ou à forma como eles estão sendo apresentados. Inclui a presença de momentos de contemplação, favorecidos pela reconstrução da cena e/ou criação de atmosfera que possibilita a contextualização do conhecimento divulgado e/ou a imersão e apreciação estética pelo público. No caso específico da criança, incluem-se elementos que são característicos das culturas infantis como a presença do imaginário (que implica a possibilidade de alteração da linearidade temporal e da lógica formal), a interatividade com os pares, a ludicidade (entendendo o brincar como possibilidade de aprendizagem), a fantasia do real (ou a "não literalidade" e presença do jogo simbólico) (SARMENTO, 2003). Para contemplar este atributo a ação de divulgação deve estimular o brincar, a interação com os pares, a presença do imaginário, a expressão, a experimentação de múltiplas linguagens. 4c Interação cognitiva. Presença de diferentes linguagens (gráfica, musical, artística, de movimento, de comunicação verbal e não-verbal, icônicas, de pensamento lógico e científico etc.), em situações que envolvam o conhecimento científico. É identificado também quando estão presentes uma ou mais habilidades investigativas na relação da criança com os objetos de conhecimento científico, como observação, afirmação, comparação, explicação, questionamento, emissão de opinião e/ou conclusão. Interação criança-criança, criança-adulto, criança-objeto em situações que envolvam o conhecimento científico, e estabelecimento de conexões entre o conhecimento científico, a vida pessoal e os conhecimentos e experiências anteriores são elementos deste atributo. No caso específico da criança, considera-se também a presença da imaginação e do brincar e sua contribuição para o desenvolvimento de funções psicológicas superiores (VYGOTSKY, 2003).

A seguir, apresentamos um quadro com a síntese de indicadores e atributos: 


\section{Quadro 1}

\begin{tabular}{|l|l|}
\hline \multicolumn{1}{|c|}{ Indicadores de AC } & \multicolumn{1}{c|}{ Atributos } \\
\hline $\begin{array}{l}\text { 1 Indicador de } \\
\text { conhecimento } \\
\text { científico }\end{array}$ & $\begin{array}{l}\text { 1a Conhecimentos e conceitos científicos } \\
\text { 1b Pesquisas científicas } \\
\text { 1c Processo de produção de conhecimento científico } \\
\text { 1d Papel do pesquisador no processo de produção do conhecimento } \\
\text { 1e Dinâmica interna da ciência. }\end{array}$ \\
\hline $\begin{array}{l}2 \text { Indicador Interface } \\
\text { Social }\end{array}$ & $\begin{array}{l}\text { 2a Impactos da ciência na sociedade } \\
\text { 2b Influência e participação da sociedade diante da ciência }\end{array}$ \\
\hline $\begin{array}{l}\text { Indicador } \\
\text { Institucional }\end{array}$ & $\begin{array}{l}\text { 3a Política e missão institucional } \\
\text { 3b Identificação das instituições envolvidas na produção, fomento e } \\
\text { divulgação da ciência }\end{array}$ \\
\hline $\begin{array}{l}\text { 4n Indicador de } \\
\text { Interação }\end{array}$ & $\begin{array}{l}\text { 4b Interação física } \\
\text { 4c Interação cognitiva }\end{array}$ \\
\hline
\end{tabular}

Fonte: autoria própria.

\subsection{LÓCUS DA PESQUISA: A BRINQUEDOTECA DO LABRIMP}

O LABRIMP - Laboratório de Brinquedos e Materiais Pedagógicos -, localizado na Faculdade de Educação da Universidade de São Paulo, é um espaço destinado à pesquisa sobre brinquedos e materiais pedagógicos, atuando como um centro de reflexão sobre o papel do brincar na formação humana. Desenvolve, dentre outras atividades, catalogação e divulgação de brinquedos e materiais pedagógicos, análise e confecção de brinquedos e brincadeiras, atendimento especializado à comunidade e oferta de oficinas a professores.

Uma das atividades desenvolvidas pelo LABRIMP é a abertura do espaço de sua brinquedoteca a crianças acompanhadas por seus familiares ou pela escola. O espaço da brinquedoteca do LABRIMP é organizado em cantos destinados a diversos tipos de atividades, contemplando áreas voltadas ao faz-de-conta, aos jogos de construção, à leitura de histórias e à produção artística.

Figura 1. LABRIMP/ Brinquedoteca. Nela é possível observar algumas das áreas da brinquedoteca: casinha, mercadinho e jogos.

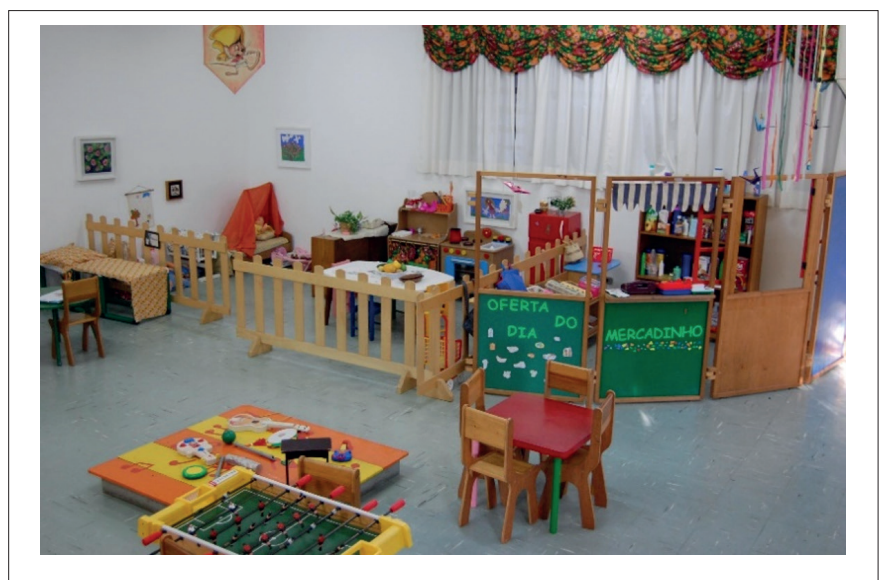

Fonte: http://www.labrimp.fe.usp.br/?action=historico. Acesso em: 01/05/2015. 
A produção de dados para esta pesquisa ocorreu no ano de 2016, mediante procedimentos de observação e de registro (fotográfico e escrito). Foram selecionadas três áreas para análise (Hospital, Casinha e Mercado), tomando-se como critério o potencial desses espaços em relação ao faz-de-conta e a situações do cotidiano das crianças, além da aproximação a aspectos da cultura científica. Os dados foram registrados em planilhas com a descrição dos objetos presentes em cada uma das três áreas em relação aos seguintes elementos: quantidade, material, dimensões, descrição física, dados de fabricação, comentários sobre possibilidade de uso, temas de ciências que podem ser explorados. Após a produção inicial, os dados foram socializados e discutidos coletivamente ${ }^{5}$ a fim de ampliarmos as considerações sobre a última coluna da tabela, qual seja, "temas de ciências".

Finalizada a produção de dados, procedeu-se à retomada de indicadores descritos na subseção anterior; tratava-se de ressignificar os atributos de modo a contemplar a criança. Questionamentos sobre a adequação da ferramenta à criança e ao espaço analisado (uma brinquedoteca) fizeram parte desse processo, considerando a indagação inicial acerca da possibilidade de considerar a criança como sujeito do processo de AC, passando pela reflexão sobre a brinquedoteca em sua função primeira (ser um espaço para o brincar livre, e não para "alfabetizar cientificamente" crianças), e sobre a ferramenta em si (inicialmente construída para análise de ações de divulgação científica em espaços como museus e centros de ciências). A apropriação de referencial teórico sobre AC e sobre infância ajudounos a optar pela utilização da ferramenta, que nos auxilia a identificar o potencial de espaços de ENF, incluindo a brinquedoteca, na promoção da AC.

A ressignificação do instrumento de indicadores e atributos foi realizada coletivamente, contando com a participação de pesquisadoras que têm se dedicado à discussão sobre $\mathrm{AC}$, crianças e ENF. ${ }^{6}$ Após a organização da ferramenta, passamos ao processo de análise dos dados produzidos, movimento inicialmente realizado de maneira individual pelas pesquisadoras que assinam este artigo para, em um segundo momento, a análise ser validada no âmbito de um grupo de pesquisa. ${ }^{7}$ Passemos, então, à análise dos dados.

\subsubsection{A INSERC̣̃̃O NA BRINQUEDOTECA: ANÁLISE DE DADOS}

\subsubsection{1- Área do Hospital}

A área do hospital é organizada simulando um consultório médico, contando com mobília, objetos alusivos ao corpo humano (esqueleto, peças que reproduzem órgãos) e ao universo saúde/doença (remédios, raios-x, avental), e quadros nas paredes que remetem ao tema. 
Figura 2. "Hospital LABRIMP". Na imagem podemos identificar a mobília (cama, mesa e lavatório), além de objetos como esqueleto, caixas de remédio (sobre o lavatório), avental (na cama), além de um microscópio (azul, sobre a mesa).

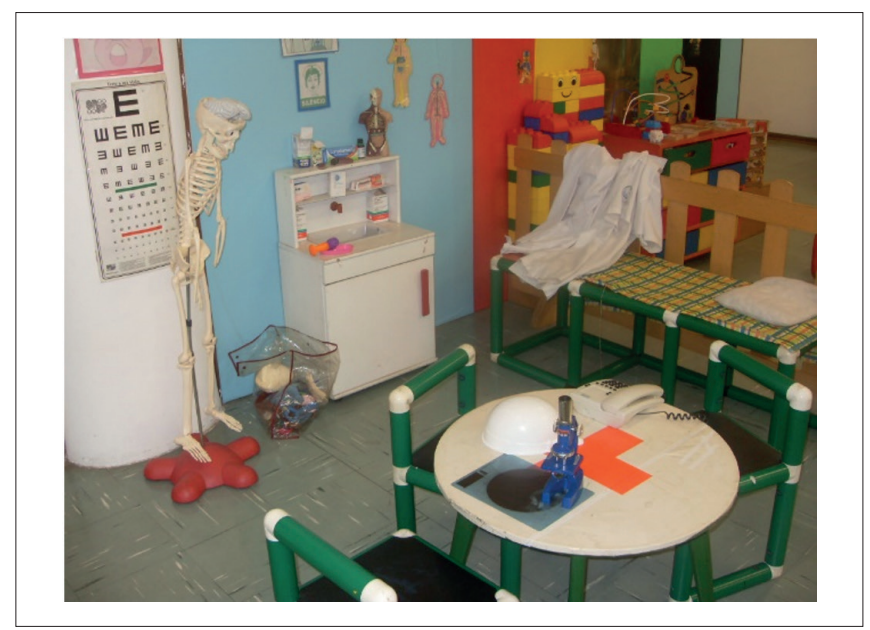

Fonte: as autoras.

A análise dos objetos presentes na área permite-nos identificar presenças e ausências de atributos e indicadores. Quanto ao Indicador de Conbecimento Científico, podemos identificar no espaço analisado a presença dos atributos: 1 a. Conhecimentos e conceitos científicos (presença de esqueleto humano, torso em resina, e representações de sistemas nas paredes); 1c. Processo de produção do conhecimento científico (possibilidade de contato com instrumentos do campo científico - microscópio -, e de vivência de métodos e procedimentos da ciência como formulação de hipóteses, realização de testes, registros, observações em uma situação de atendimento médico). No que toca ao Indicador Interface Social, podemos identificar os atributos: 2 a. Impacto da ciência na sociedade (possibilidade de estabelecimento de conexões do conhecimento científico com o cotidiano e com as vivências pessoais da criança relacionadas a saúde/doença, atendimento médico, hospital etc.; objetos como acetatos de raio-x, caixas de remédio, teste de visão colado na parede, avental médico e maleta médica com acessórios remetem a esse universo); 2b. Influência e participação da sociedade diante da ciência (possibilidade de realização de escolhas relacionadas à saúde, o que remete à participação social e ao processo de tomada de decisão). No que diz respeito ao Indicador Institucional, na área do Hospital não se faz presente nenhum dos atributos. Quanto ao Indicador de Interação, verifica-se a presença dos seguintes atributos: 4a. Interação física (o espaço é destinado à brincadeira, e possibilita a manipulação de objetos e o respeito ao tempo e ao ritmo da criança); 4b. Interação estético-afetiva (há a possibilidade de respostas pessoais, presença do imaginário - trata-se de um espaço para o faz-de-conta -, interatividade com os pares, ludicidade, jogo simbólico, expressão em situações que envolvem conhecimento científico); 4c. Interação cognitiva (fazem-se presentes diferentes linguagens, a possibilidade de vivência de habilidades investigativas, a interação, o estabelecimento de conexões com o cotidiano, o brincar). 


\subsubsection{2- Área do Mercado}

Delimitado por um biombo no qual há uma placa com a inscrição "Mercado", e outra com um aviso sobre a não aceitação de cheques e cartões, possui uma banca de madeira na qual são dispostas frutas de plástico, além de uma estante com prateleiras nas quais são organizadas embalagens vazias dos mais diversos produtos. Conta também com uma mesa com caixa registradora e telefone, além de uma reprodução de caixa eletrônico para realização de saques em dinheiro.

Figura 3 e 4. Área do Mercado. Na fig. 3 vê-se a delimitação da área, e o "caixa eletrônico" à direita; a fig. 4 permite-nos uma visualização da bancada (com telefones e registradora) e das prateleiras com os produtos comercializados. Tem-se uma visão parcial da bancada de frutas ao fundo, à direita, na figura 4.

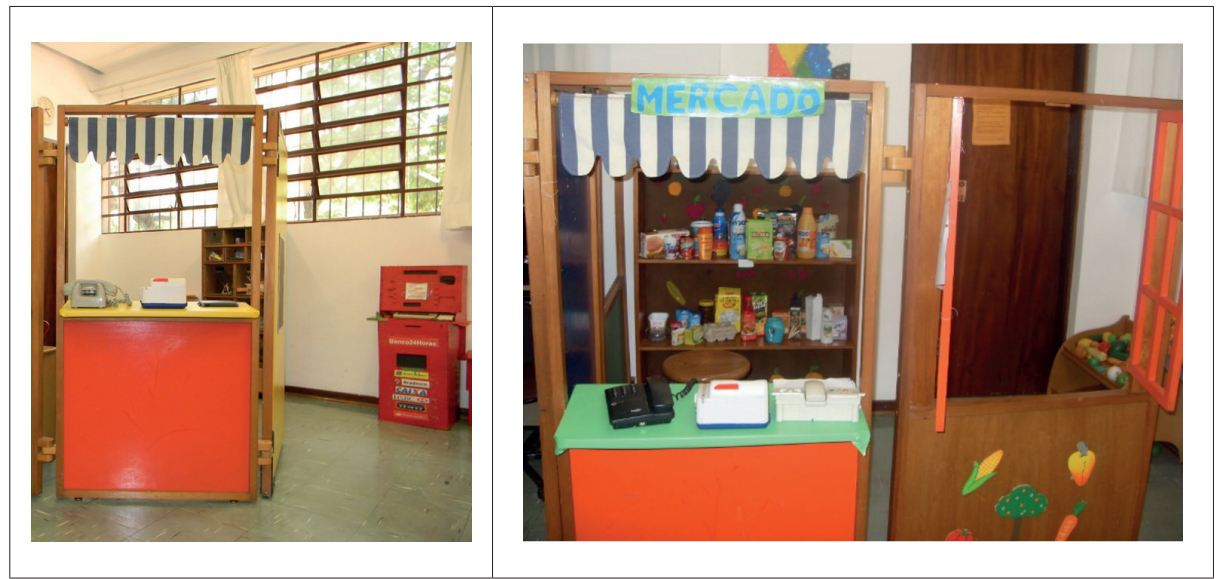

Fonte: as autoras.

A análise dos objetos presentes na área permite-nos considerar a presença dos seguintes indicadores: 1. Indicador de Conbecimento Científico, no atributo 1a. Conhecimentos e conceitos científicos (a presença de frutas de brinquedo e embalagens de produtos, em um contexto de mercado, remete a questões relativas a alimentação e hábitos alimentares, conservação de alimentos, pesos, medidas, higiene); 2. Indicador Interface Social, nos atributos $2 \mathrm{a}$. Impacto da ciência na sociedade (possibilidade de estabelecimento de conexões do conhecimento científico com o cotidiano e com as vivências pessoais da criança relacionadas à alimentação e higiene; contato com impacto da ciência na sociedade mediante produtos tecnológicos como telefone, caixa eletrônico e registradora); 2 b. Influência e participação da sociedade diante da ciência (possibilidade de realização de escolhas relacionadas a alimentação e consumo, o que remete à participação social e ao processo de tomada de decisão em contextos que impliquem conhecimento científico; a presença de diferentes produtos alimentícios favorece esse processo de escolha); 4. Indicador de Interação, em seus três atributos, como na área do Hospital, e pelos mesmos motivos. O Indicador Institucional não se fez presente. 


\subsubsection{3- Área da Casinha}

Esta área reproduz o ambiente de uma pequena casa, dividida, com o auxílio do mobiliário, em diferentes cômodos: quarto, cozinha, sala, área de serviço, como observamos na figura abaixo:

Figura 5. Área da Casinha. Tem-se uma visão geral da área, observando-se a organização em "cômodos"; tanque, sofá, cama, mesa, armário, geladeira, fogão podem ser vistos.

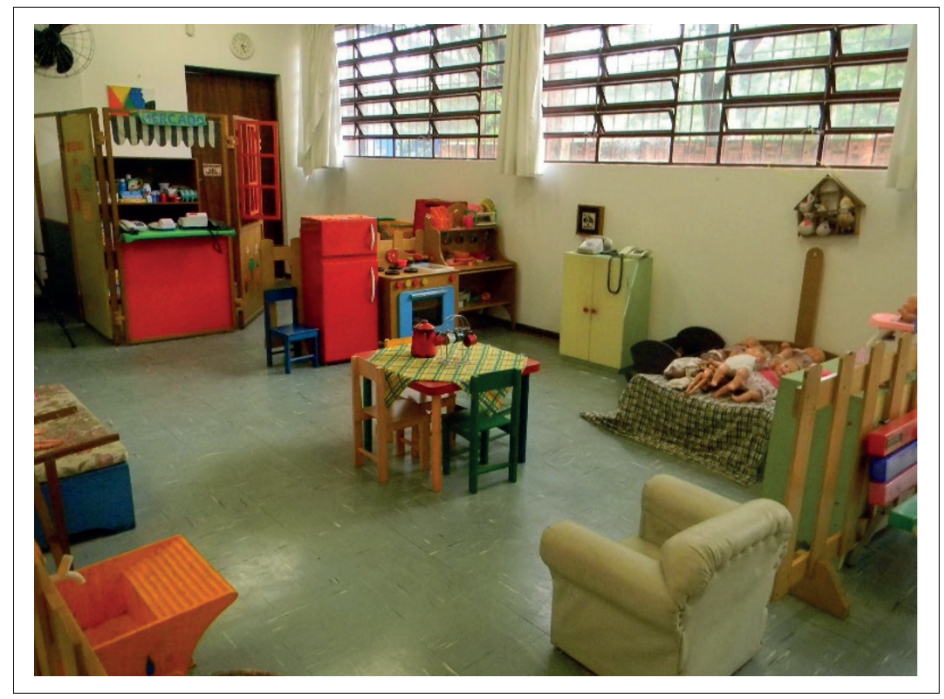

Fonte: as autoras.

Também nesta área se fazem presentes os indicadores 1, 2 e 4, ainda que não seja contemplada a totalidade dos atributos. No Indicador de Conbecimento Científico observa-se apenas o atributo $1 \mathrm{a}$. Conhecimentos e conceitos científicos (a presença de fogão e geladeira podem remeter a questões como temperatura, mudança de estados físicos, transformação e composição dos alimentos; as bonecas-bebês possibilitam a discussão sobre o cuidar - alimentação, higiene, saúde/doença; a "área de serviço" promove a discussão sobre questões de higiene). No Indicador Interface Social, assim como nas áreas já analisadas, identifica-se o atributo $2 \mathrm{a}$. Impacto da ciência na sociedade (possibilidade de estabelecimento de conexões do conhecimento científico com o cotidiano e com as vivências pessoais da criança relacionadas a cuidados pessoais, alimentação e higiene; contato com impacto da ciência na sociedade mediante produtos tecnológicos como telefone, fogão, geladeira). Quanto ao Indicador Institucional, não se faz presente nenhum dos atributos. Quanto ao Indicador de Interação, todos os atributos são contemplados: há a possibilidade de manipulação de objetos e de respeito ao tempo e ao ritmo da criança (interação física); há a possibilidade de respostas pessoais, presença do imaginário, interatividade com os pares, ludicidade, jogo simbólico, expressão em situações que envolvem conhecimento científico (interação estético-afetiva); fazem-se presentes diferentes linguagens, 
possibilidade de vivência de habilidades investigativas, interação, estabelecimento de conexões com o cotidiano, brincar (interação cognitiva).

\subsection{DISCUSSÃO: SOBRE PRESENC̣AS E AUSÊNCIAS DE INDICADORES DE AC}

Inicialmente cabe destacar que as diferentes áreas apresentaram regularidade no que toca à presença dos atributos; em todas elas fizeram-se presentes os atributos $1 \mathrm{a}, 2 \mathrm{a}, 4 \mathrm{a}, 4 \mathrm{~b}, 4 \mathrm{c}$, ainda que as temáticas trabalhadas sejam distintas em cada um dos espaços. Além destes, a área do Hospital apresentou também o atributo 1c (Processo de produção de conhecimento científico), e o Mercado e o Hospital, o atributo 2b (Influência e participação da sociedade diante da ciência). Desse modo, os espaços analisados potencializam o contato com ideias e conhecimentos científicos (atributo 1a), o diálogo com as experiências do cotidiano em sua interface com a ciência e a tecnologia (atributo 2a), e são caracterizados pelas múltiplas possibilidades de interação (atributos 4a, 4b, 4c).

Analisando comparativamente os três espaços, evidencia-se que a área do "Hospital" apresenta um atributo a mais (1c), que remete ao processo de produção do conhecimento científico. No que toca ao atributo 1a (conhecimentos, ideias e conceitos científicos), também se verifica a ocorrência de uma quantidade maior de evidências nessa área, sendo estas mais facilmente identificáveis do que aquelas presentes nos demais espaços analisados. Hospital remete, por sua natureza, a discussões sobre saúde, doença, anatomia e fisiologia humanas, dialogando de maneira explícita com temas científicos.

Em relação ao Mercado e ao Hospital, constatou-se a presença do atributo 2b (Influência e participação da sociedade diante da ciência). A presença de diversos produtos para "comercialização" no Mercado potencializa o processo de escolha e tomada de decisão em um tema que implica conhecimento científico; não se trata apenas de fazer escolhas, mas de escolher que alimentos comprar diante da oferta do mercado, o que dialoga com o atributo. No caso do Hospital, entendemos que a organização da área possibilita discussões e decisões sobre formas de manutenção da saúde, cuidados com o bem-estar físico e mental, utilização de medicamentos, dentre outros.

No que tange à análise conjunta dos três espaços, constata-se a escassa presença dos demais atributos do Indicador 1 (Produção de conhecimento científico); de cinco atributos, apenas dois se fazem presentes (1a, nas três áreas, e 1c, no Hospital e no Mercado), o que pode ser justificado pela natureza do espaço da brinquedoteca, que tem por função promover o brincar livre (CUNHA, 1997), sem o propósito de possibilitar a aproximação do público a dimensões relacionadas à natureza da ciência.

O Indicador 2 (Interface Social) é contemplado em seus dois atributos, sendo que o 2 a (impactos da ciência na sociedade) fez-se presente nos três espaços, enquanto que o 2 b (influência e participação da sociedade diante da ciência) foi identificado nas áreas do Mercado e do Hospital. Em relação a esse indicador, cabe destacar a presença da tecnologia; microscópio, caixa registradora, telefone, e mesmo objetos como pratos, garfos e panelas fazem-se presentes nos espaços, potencializando o contato da criança com a dimensão dos artefatos, expressão da relação ciência-tecnologia e da técnica como mediação exercida pela ação humana 
em sua relação com o ambiente (VIEIRA PINTO, 2005).

Quanto ao Indicador 3 (Institucional), percebe-se sua ausência no espaço estudado. Entende-se que o atributo 3a deste indicador, relativo a política e missão institucional, somente faz sentido em locais especialmente voltados para a divulgação científica, não sendo este o caso de uma brinquedoteca. $\mathrm{O}$ atributo $3 \mathrm{~b}$ (identificação das instituições envolvidas na produção, fomento e divulgação da ciência), poderia ser fomentado por meio da inserção, nos espaços, de referências a essas instituições via cartazes, por exemplo. Ainda no que tange ao indicador institucional, vale a pena destacar que o espaço da brinquedoteca é organizado em espaços e materiais adequados ao público infantil. Iszlaji (2012), apoiada em Forneiro (2008), destaca em seu trabalho a relevância de que os espaços de educação não formal garantam a adequação do espaço físico voltado para a criança, o que nem sempre ocorre nos museus de ciências, por exemplo. Assim, é fundamental que o encontro da cultura da infância com a cultura científica dê visibilidade a esses aspectos ao se pensar a alfabetização científica por meio dos espaços culturais. Trata-se de analisar o espaço físico e suas condições estruturais (dimensões, ventilação, iluminação), os objetos (mobiliários e materiais) e sua organização (modos de distribuição no espaço) em sua adequação ao público infantil, potencializando a participação deste nas ações de divulgação científica.

A presença dos três atributos do Indicador 4 (Indicador de Interação) reforça a percepção de se tratar de um espaço planejado especificamente para a criança e para o brincar, constatando-se a possibilidade de manipulação de objetos e de respeito ao tempo e ao ritmo da criança (interação física); possibilidade de respostas pessoais, presença do imaginário, interatividade com os pares, ludicidade, jogo simbólico, expressão em situações que envolvem conhecimento científico (interação estético-afetiva); presença de diferentes linguagens, possibilidade de vivência de habilidades investigativas, interação, estabelecimento de conexões com o cotidiano, brincar (interação cognitiva). Lembramos que garantir espaço à interação e ao brincar significa potencializar a produção das culturas infantis, considerando sua natureza interpretativa e social (trata-se de culturas de pares, que dialogam com elementos da cultura mais ampla); significa tomar a criança como ponto de partida, e possibilitar sua aproximação a elementos da cultura científica (conceitos, termos, procedimentos, linguagem etc.) a partir de vivências que respeitem seus tempos e dialoguem com suas infâncias.

Entendendo que a brinquedoteca não se configura enquanto espaço que tem por objetivo inicial promover ações de divulgação científica, podemos considerar que foi encontrado um importante potencial deste local na promoção da AC de crianças. Essa afirmação se sustenta de forma especial ao retomarmos os referenciais teóricos discutidos, que colocam luz à importância do brincar no processo de produção das culturas infantis, culturas essas que reproduzem e reinterpretam elementos da cultura mais ampla (CORSARO, 2011; SARMENTO, 2003). Poder brincar de hospital e nele manipular um esqueleto de brinquedo ou um microscópio possibilita o contato com elementos da cultura científica, assim como escolher os produtos no mercado, realizar saque no caixa eletrônico, preparar uma refeição, cuidar de um bebê. 
A organização do espaço pode potencializar a inserção de temáticas que remetam a conhecimentos científicos nas brincadeiras, mas não podemos nos esquecer de que a criança, ao brincar, tem a possibilidade de romper com a lógica inicialmente estabelecida. À incerteza do brincar e das aprendizagens dele decorrentes Brougère (2008) responde com a proposta de construção de um "ambiente indutor", destacando a importância de inserir objetos que potencializem os objetivos almejados - em nosso caso, a AC. Isto porque o brinquedo é fonte de impregnação cultural da criança, apresentando-lhe imagens, símbolos e representações:

O educador pode, portanto, construir um ambiente que estimule a brincadeira em função dos resultados desejados. Não tem certeza de que a criança vá agir, com esse material, como desejaríamos, mas aumentamos, assim, as chances de que ela o faça; num universo sem certezas, só podemos trabalhar com probabilidades. Portanto, é importante analisar seus objetivos e tentar, por isso, propor materiais que otimizem as chances de preencher tais objetivos. (BROUGÈRE, 2008, p. 105)

Ainda que possamos destacar as possibilidades, faz-se necessário também refletir sobre as ausências; nesse sentido, a análise a partir de indicadores pode auxiliar na promoção de transformações no ambiente. Por exemplo, a inserção de um painel no Hospital com a referência a pesquisadores que diagnosticaram algumas doenças poderia promover uma aproximação ao reconhecimento do papel do pesquisador no processo de produção do conhecimento (atributo 1d); a inserção, na Casinha, de lixeiras de separação de resíduos e cartazes relativos a problemáticas contemporâneas como crise hídrica ou poluição ambiental possibilitaria a reflexão sobre a influência e a participação da sociedade diante da ciência (atributo $2 b$ ). Outra hipótese seria a de inserir na brinquedoteca outras áreas como laboratório (possibilitando à criança brincar com instrumentos como lupas, microscópios, béqueres, balança, conta-gotas, líquidos coloridos etc.), ou mesmo espaços que incluíssem objetos científicos como coleções de folhas ou insetos, cartazes, miniaturas de seres vivos, quebra-cabeças de animais, dentre outros.

A realização de pesquisa durante o ato de brincar das crianças poderia revelar presenças e ausências diferentes daquelas constatadas nesta investigação. Isto porque, conforme explicitado, a criança, ao brincar, transgride a lógica inicialmente estabelecida por espaços e tempos, uma vez que imaginário, interatividade, ludicidade e não literalidade (SARMENTO, 2003) caracterizam as culturas infantis.

\section{CONSIDERACְÕES FINAIS}

À luz do referencial teórico-metodológico adotado, apontamos a importância de considerar a criança como sujeito do processo de AC, contemplando suas especificidades. Indicamos a relevância de avaliar o potencial de espaços de educação não formal na promoção da AC, incluindo a criança (LORENZETTI, DELIZOICOV, 2001). Concluímos que a brinquedoteca pode contribuir para o processo de AC de crianças, possibilitando a aproximação das culturas infantis a elementos da cultura científica. Indicamos também que as potencialidades podem ser ampliadas mediante a inserção de objetos ou espaços que promovam a aproximação 
da criança a elementos da cultura científica não contemplados na análise inicial, sem que isso signifique desconsiderar o brincar livre, o imaginário e as culturas de pares.

Defendemos que, ao tratarmos das relações entre criança, infância e ciência, objetiva-se fomentar o acesso a saberes do campo científico, promovendo a interlocução entre culturas da infância e elementos da cultura científica (FAGGIONATO-RUFINO, 2012). Para tal, cabe destacar a importância do lúdico e, especificamente, da brincadeira como linguagem privilegiada da criança (VYGOTSKY, 2003), bem como a importância das interações nesse processo de apropriação do mundo e construção de significados (KISHIMOTO, 2011; SARMENTO, 2003; CORSARO, 2011). Destaque também à dimensão material do espaço, à centralidade da construção de um ambiente que promova a ampliação da experiência cultural da criança (BROUGÈRE, 2008), o que inclui a cultura científica.

Esperamos que os achados desta pesquisa possam contribuir para a construção de ambientes desafiadores e enriquecidos para as crianças, capazes de promover a ampliação de suas experiências de aprendizagem relacionadas ao processo de alfabetização científica, sejam eles desenvolvidos em espaços de educação formal ou não formal. Esperamos também que o artigo possa trazer contribuições especialmente ao campo da educação não formal, de modo que a criança possa ser cada vez mais considerada sujeito e partícipe em ações de divulgação científica, sem que isso implique a negação de seu imaginário, suas linguagens, suas infâncias.

\section{AGRADECIMENTOS}

Agradecemos aos bolsistas Samuel Feitosa Vanique e Marcela Espósito Baena do Programa Aprender com Cultura e Extensão da PRCEU/USP pelo auxílio na coleta dos dados no Labrimp.

\section{REFERÊNCIAS}

ACHIAM, M.; MARANDINO, M. A framework for understanding the conditions of science representation and dissemination in museums. Museum Management and Curatorship, v. 29, n.1, p. 66-82, 2014.

AKERSON, V. L.; BUCK, G. A.; DONNELLY, L. A.; NARGUND-JOSHI, V.; WEILAND, I. S. The Importance of Teaching and Learning Nature of Science in the Early Childhood Years. Journal of Science Education and Technology, 20(5), p. 537-549, 2011.

ANDERSON, D.; PISCITELLI, B.; WEIER, K.; EVERETT, M.; TAYLER, C. Children's Museum Experiences: Identifying Powerful Mediators of Learning. Curator, v. 45, n.3, p. 213-231, 2002.

ASH, D. The process skills of inquiry. In: ASH, D. Inquiry in the $\mathbf{K}-\mathbf{5}$ classroom: Foundations, v. 2, 1999. Washington, DC: National Science Foundation, p. 51-62, 1999.

AULER, D.; DELIZOICOV, D. Alfabetização científico-tecnológica para quê? Ensaio: pesquisa em educação em ciências, v.3, n.1, p.105-115, 2001.

BENJAMIN, W. Reflexões sobre o brinquedo, a criança e a educação. São Paulo: Ed. 34, 2009. 
BROUGÈRE, G. Brinquedo e cultura. $7^{\mathrm{a}}$ ed. São Paulo: Cortez, 2008.

BYBEE, R.W. Achieving Scientific Literacy. The Science Teacher, v. 62, n. 7, p. 28-33, 1995.

CACHAPUZ, A.; GIL-PEREZ, D.; CARVAlHO, A. M. P. de; VILCHES, A. A necessária renovação do ensino das ciências. São Paulo: Cortez, 2011.

CARVALHO, C.; LOPES, T. O público infantil nos museus. Educação e Realidade, Porto Alegre, v. 41, n. 3, p. 911-930, jul./set. 2016.

CERATI, T. Educação em Jardins Botânicos na perspectiva da Alfabetização Científica: análise de uma exposição e público. 2014. 213f. Tese (Doutorado em Educação) - Faculdade de Educação da USP, São Paulo.

CHASSOT, A. Alfabetização científica: questões e desafios para a educação. $6^{a}$ ed. Ijuí: Editora Unijuí, 2014.

CORSARO, W. A. Sociologia da Infância. Porto Alegre: Artmed, 2011.

CUNHA, N. H. S. A brinquedoteca Brasileira. In: SANTOS, S. M. P. (Coord.) Brinquedoteca: o lúdico em diferentes contextos. Petrópolis: Vozes, 1997.

EDWARDS, C., GANDINI, L., FORMAN, G. As cem linguagens da criança: a abordagem de Reggio Emilia na educação da primeira infância. Porto Alegre: Artes Médicas Sul, 1999.

FAGGIONATO-RUFINO, S. O diálogo entre aspetos da cultura científica com as culturas infantis na educação infantil. 2012. 215 f. Tese (Doutorado em Educação) - Centro de Educação e Ciências Humanas, UFSCar, São Carlos.

FERNANDES, F. Folclore e mudança social na cidade de São Paulo. São Paulo: Martins Fontes, 2004.

FNQ. Sistema de Indicadores: Fundação Nacional da Qualidade. Disponível em http://www.fnq. org.br/informe-se/publicacoes/e-books. Acesso em: 17 jun. 2016.

FORNEIRO, M. L. I. Observación y evaluación del ambiente de aprendizaje em educación infantil: dimensiones y variables a considerar. Revista Iberoamericana de Educación, n. 47, p. 49-70, 2008.

FOUREZ, G. Crise no ensino de ciências? Investigações em Ensino de Ciências, v. 8, n. 2, p. 109-123, 2003.

FREIRE, P. A importância do ato de ler: em três artigos que se completam. São Paulo: Autores Associados: Cortez, 1989.

GARFIELD, E. Science Literacy. Part 1. What is Science literacy and why is it important? Essays of an Information Scientist: Science Literacy, Policy, Evaluation, and other Essays, v. 11, p. 251-257, 1988.

HENRIKSEN, E.; FROYLAND, M. The contribution of museums to scientific literacy: views from audience and museum professionals. Public Understanding of Science, v. 9, n. 4, p. 393415, out. 2000 .

ISZLAJI, C. A criança nos museus de ciências: análise da exposição Mundo da Criança do Museu de Ciência e Tecnologia da PUCRS. 2012. 256 f. Dissertação (Mestrado em Ensino de Ciências) - Faculdade de Educação, Instituto de Física, Instituto de Química, Instituto de Biociências, Universidade de São Paulo, São Paulo. 
JENKS, C. Constituindo a Criança. Educação, Sociedade e Culturas, Porto: Afrontamento, n. 17, p. 185-216, 1994.

JENSEN, M. Children's perceptions of their museum experience: A contextual perspective. Children's Environments Quarterly, v. 4, p. 300-324, 1994.

KISHIMOTO, T. M. O jogo e a educação infantil. São Paulo: Cengage Learning, 2011.

KRASILCHIK, M. Ensino de ciências: um ponto de partida para a inclusão. In: WERTHEIN J.; CUNHA, C. Ensino de ciências e desenvolvimento: o que pensam os cientistas. $2^{\mathrm{a}}$ ed. Brasília: Unesco, Instituto Sangari, 2009.

KRASILCHIK, M.; MARANDINO, M. Ensino de ciências e cidadania. São Paulo: Moderna, 2007.

LAUGKSCH, R. C. Scientific Literacy: a conceptual overview. Science Education, v. 84, n. 1, p. 71-94, 2000.

LEWENSTEIN, B.; BROSSARD, D. Assessing models of public understanding in ELSI outreach materials, USA: Department of Energy: Final Report. Cornell: Cornell University, 2006.

LORENZETTI, L.; DELIZOICOV, D. Alfabetização científica no contexto das séries iniciais. Ensaio - Pesquisa em Educação em Ciências, v. 3, n. 1, p. 1- 17, jun. 2001.

MARANDINO, M. (org.). Educação em museus: a mediação em foco. São Paulo, SP: Geenf/ FEUSP, 2008.

MARANDINO, M.; MARTINS, L. C. GRUZMAN, C.; CAFFAGNI, C. W.; ISZLAJI, C.; CAMPOS, N. F.; MÔNACO, L.; SALGADO, M.; FIGUEROA, A. M. S. BIGATTO, M. A abordagem qualitativa nas pesquisas em educação em museus. In: VII ENCONTRO NACIONAL DE PESQUISA EM EDUCAÇÃO EM CIÊNCIAS, 2009, Florianópolis: VII ENPEC. Atas... Florianópolis, 8-13 nov. 2009. s/p.

MILLER, J. D. The measurement of civic scientific literacy. Public Understand of Science, v. 7 , p. 203-223, 1998.

MARQUES, A. C. T. L.; SCALFI, G. A. de M.; ISZLAJI, C.; MARTINS, B. M.; MARANDINO, M. Alfabetização científica e criança: uma proposta de ferramenta teórico-metodológica para análise de ações educativas em espaços de educação não formal. In: XI ENCONTRO NACIONAL DE PESQUISA EM EDUCAÇÃO EM CIÊNCIAS, 2017, Florianópolis. Anais... Florianópolis: XI ENPEC, 2-6, julho 2017. s/p.

MARQUES, A. C. T. L.; MARANDINO, M. Alfabetização científica, criança e espaços de educação não formal: diálogos possíveis. Educação e Pesquisa, São Paulo, v. 44, p. 1-19, 2018.

NEVES, R.; MASSARANI, L. O olhar das crianças sobre uma exposição interativa. In: MASSARANI, L; NEVES, R.; AMORIM, L. (Org). Divulgação científica e museus de ciências: O olhar do visitante - Memórias do evento. Rio de Janeiro: Museu da Vida/Casa de Oswaldo Cruz/Fiocruz; RedPop, 2016.

NGSS. Next Generation Science Standards: For States, By States. Washington, DC: The National Academies Press, 2013.

NORRIS, S. P.; PHILLIPS, L. M. How literacy in its fundamental sense is central to scientific literacy. Science Education. v. 87, n. 2, p. 224-240, 2003. 
OLIVEIRA, D. Biodiversidade em políticas públicas de Ciência, Tecnologia e Inovação: caracterização e perspectivas para a integração do fomento à divulgação e educação científicas. 2016. Tese (Doutorado em Educação em Ciências) - Universidade Federal do Rio Grande do Sul, Rio Grande do Sul.

PÉREZ, C. A.; MOLINÍ, A. M. V. Consideraciones generales sobre la alfabetización científica em los museos de la ciencia como espacios educativos non formales. Revisa Electrónica de Enseñanza de las Ciencias, v. 3, n. 3, p. 1-26, 2004.

PISCITELLI, B. EVERETT, M.; WEIER, K. Enhancing Young Children's Museum Experiences: a manual for museum staff, QUT, Brisbane, 2003. Disponível em: https://hollandmvp.files.wordpress. com/2014/07/enhancing-young-childrens-museum-experiences.pdf Acesso em: 24 jun. 2016.

QVORTRUP, J. Childhood Matters: An Introduction. In: QVORTRUP, J.; BARDY, M.; SGRITTA, G.; WINTERSBERGER, H.; HERNANDEZ, D. J. Childhood Mattters: Social Theory, Practices and Politics. Aldershot: Avebury, 1994.

ROBERTS, D. A. Scientific Literacy/Science Literacy. In: ABELL, S. K.; LEDERMAN, N. G. Handbook of Research in Science Teaching and Learning. New York: McMillan, 2007.

SANTOS, W. L. P.; MORTIMER, E. D. Tomada de Decisão para Ação Social Responsável no Ensino de Ciências. Ciência \& Educação, v. 7, n. 1, p. 95-111, 2001.

SANTOS, W. L. P. Educação científica na perspectiva de letramento com prática social: funções, princípios e desafios. Revista Brasileira de Educação, v. 12. n. 36, p. 474-550, set./ dez. 2007.

SARMENTO, M. J. Gerações e Alteridade: Interrogações a partir da Sociologia da Infância. Educação e Sociedade, n. 26 (91), p. 361-378, 2005.

SARMENTO, M. J. Imaginários e culturas da infância. Cadernos de Educação, Pelotas, v. 12, n. 21, p. 51-69, 2003.

STUDART, D. C. Museus e famílias: percepções e comportamentos de crianças e seus familiares em exposições para o público infantil. História, Ciências, Saúde, Manguinhos, RJ, v. 12 (suplemento), p. 55-77, 2005.

SIS CATALYST. Children As Change Agents For the future of science \& society. 2013. Disponível em: <http://www.siscatalyst.eu> Acesso em: 22 fev. 2016.

TRILLA, J.; GROS, B.; LÓPEZ, F.; MARTÍN, M. La educación fuera de la escuela. Ámbitos no formales y educación social. Barcelona: Ariel Educación, 2003.

VIEIRA PINTO, A. O conceito de tecnologia. Vol. 1. Rio de Janeiro: Contraponto, 2005.

VYGOTSKY, L. S. A formação social da mente. São Paulo: Martins Fontes, 2003.

\section{NOTAS}

${ }^{1} \mathrm{O}$ autor define cultura lúdica como o "conjunto de regras e significações próprias do jogo que o jogador adquire e domina no contexto de seu jogo" (BROUGÈRE, 1998, s/p.), conjunto de procedimentos que tornam o jogo possível. Não nos deteremos neste elemento uma vez que nosso interesse recai sobre as possibilidades de apropriação, pela criança, na brincadeira, de elementos da ciência. 
${ }^{2}$ De acordo com Marandino et al. (2009), as pesquisas qualitativas em museus podem ser classificadas em função dos objetivos e finalidades em estudos de concepscão, "voltados para a compreensão dos fundamentos utilizados para conceber e planejar as atividades educacionais e comunicacionais" (MARANDINO et al., 2009, p. 7), e estudos de recep̧são, "voltados para compreensão dos processos de aprendizagem do público que participa das atividades educacionais" (MARANDINO et al., 2009, p. 7).

${ }^{3}$ De acordo com Marandino et al. (2009), as unidades de estudo referem-se às atividades educacionais estudadas, que podem ser: exposições e ações educativas (visitas à exposição, monitorias, oficinas, materiais didáticos, formação de professores, etc.). Na pesquisa apresentada neste artigo tivemos como foco de análise a "exposição" em si, ou seja, o modo como os espaços e os objetos são apresentados.

${ }^{4}$ Os atributos auxiliam na compreensão e mensuração de cada indicador. Os atributos englobam questões contemporâneas de discussões e concepções da AC e podem fornecer dados mensuráveis e passíveis de comparação com outros estudos, com informações qualitativas e quantitativas.

${ }^{5}$ A pesquisa contou com apoio de dois bolsistas do programa Aprender com Cultura e Extensão da PróReitoria de Cultura e Extensão da USP, que participaram dos procedimentos de produção e análise dos dados.

${ }^{6}$ A discussão deu origem a um artigo apresentado no XI Encontro Nacional de Pesquisa em Educação em Ciências - ENPEC, realizado em Florianópolis no ano de 2017. Referência: MARQUES et al. (2017).

${ }^{7}$ Grupo de Estudos e Pesquisa em Educação Não Formal e Divulgação em Ciência - GEENF.

Submetido em 28/07/2018
Aprovado em 09/01/2019

Contato:

Instituto Federal de Educação, Ciência e Tecnologia de São Paulo

Campus São Paulo

R. Pedro Vicente, n. 625, Bairro Canindé.

CEP 01.109-010 - São Paulo, SP- Brasil 